\title{
Financial Stochastic Modeling and the Subprime Crisis
}

\author{
Aitoutouhen Latifa ${ }^{1}$, Hamza Faris ${ }^{2}$ \\ ${ }^{1}$ Faculty of Economics, University Abdel Malek Essaâdi, Tangier, Tetouan, Morocco \\ ${ }^{2}$ Polydisciplinary Faculty, University Abdel Malek Essaâdi, Tetouan, Morocco \\ Email address: \\ latifa_ait@hotmail.com (A. Latifa), fhamza2004@yahoo.fr (H. Faris)
}

\section{To cite this article:}

Aitoutouhen Latifa, Hamza Faris. Financial Stochastic Modeling and the Subprime Crisis. International Journal of Economics, Finance and Management Sciences. Vol. 4, No. 2, 2016, pp. 67-77. doi: 10.11648/j.ijefm.20160402.15

Received: February 17, 2016; Accepted: March 1, 2016; Published: March 12, 2016

\begin{abstract}
This present paper proposes to study the limits of mathematical models and their assumptions through the subprime crisis initiated at the summer 2007. Indeed, the mathematical modeling is one of the causes that have contributed to the bursting and the propagation of this financial collapse at the planetary level. However, the valorization of complex products such as (CDO and CDS) was supported by the use of the function of the 'Gaussian Copula' combined with the adoption of restrictive and erroneous assumptions. More precisely, this article aims to provide answers to the following interrogations: Which are the risks related to stochastic models, and which are the tools to evaluate and control them as well as the axes of reflection to solve this crisis of modeling?
\end{abstract}

Keywords: Finance Markets, Stochastic Modeling, Subprime Crisis, Credit Derivatives (CDO and CDS), Securitization, Gaussian Copula

\section{Introduction}

The mathematical models occupy a fundamental place within modern finance. In fact, they are means of decision support for different market agents and instruments for promoting financial markets operations. However, their use has been heavily criticized these last decades because of the appearance of the financial crises.

In this regard, several recent crises have affected the financial markets, that the stochastic models could not predict them. For example, the slump in prices of Dow- Jones of $22.6 \%$ on October 19th, 1987 in one day, the bankruptcy of the LTCM fund in 1998, and the systemic risk which it could generate for the international financial markets.

All those crisis led to seriously ask questions about the advanced mathematical models of point including the famous model of evaluation of the options "Black, Scholes and Robert Merton".

Other remarkable events, such as the Asian crisis of 1997-1998 and the bursting of bubble Internet in March 2000, have strongly shaken the stock markets, but without either calling into question the bases of financial industry. But for the last crisis, it is the most essential aspect of the financial industry which is seriously affected in terms of its ability to develop and innovate the financial products as well as to transfer and manage the risk (e.g. subprime).

The famous subprime crisis that started in 2007, whose roots went back to the 2000 s, was the worst crisis the United States has experienced after the Great Depression of 1930. This crisis was extremely widespread in other countries occurring in the financial sector and deepening afterwards in the real economy.

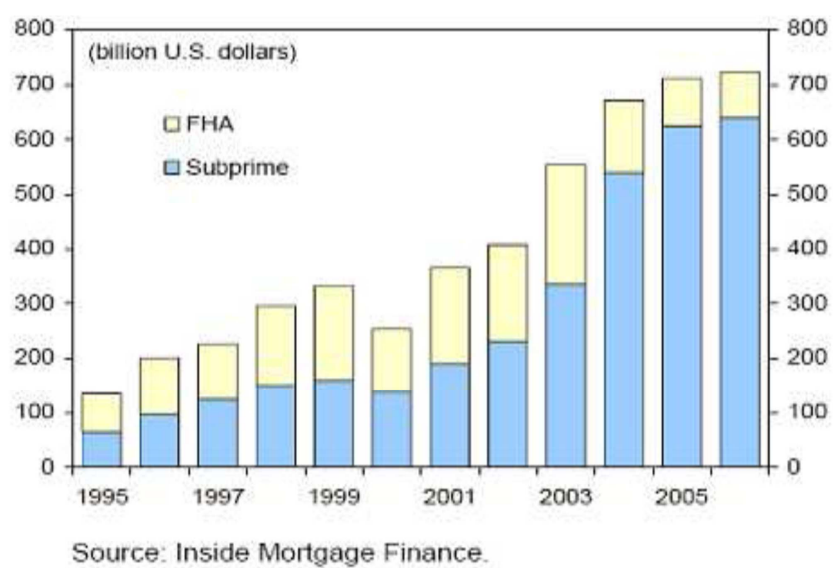

Figure 1. Evolution of subprime loans. 
Therefore, the US housing market was at the heart of this turmoil. For this reason, the US government has established very favorable macro financial conditions to facilitate home ownership. Thus, credit institutions (the initiator) and brokers have granted the US households little or insolvent subprime loans without prior in-depth study of the risks.

Furthermore, between 2000 and 2006, property prices have been increased thanks to the favorable conditions of having access to credits and speculation on the stock market. For this reason, some mortgagors offered an extremely low rate period of two or three years. So with the end of 2006 and with the rapid increase in rates, many households could not pay their debts nor sell their property that had lost much of its value, and that led to numerous seizures and real estate sales and consequently the decline of asset backed securities.

Thus, the institutional investors have given up buying these securities which generated a crisis of liquidity. The deposit banks massively repatriated in their accounts these toxic credits which they had created off balance sheet. The loss of confidence was widespread and the interbank market has fallen into recession. In addition, the situation has been worsened by the dissemination of information deficit and lack of ethics as well as the implementation of certain international accounting standards that precipitated the bankruptcy of these banks.

The magnitude of the crisis and its generalization were due to the securitization of mortgages with technical risk which might force a bank to resell them in specialized markets. These have developed hyper complex, incomprehensible and sophisticated products including $\mathrm{CDS}, \mathrm{CDO}$ and $\mathrm{CDO}^{2}$ which have enabled us to conceal and easily transfer the risks of these loans.

During the 2007-2008 financial crises, these hyper complex financial instruments have contributed greatly to dissimulate the extent of debt level as well as the risks resulting from the most used instruments. Moreover, it has been difficult to assess or quantify the risks that might incur a financial institution to hold any of these instruments.

The current crisis has resulted therefore in questioning the quantitative management methods and risk assessment primarily of debt securities CDO and CDS. So, how could modeling of these credit derivatives be worse at this point for this crisis?

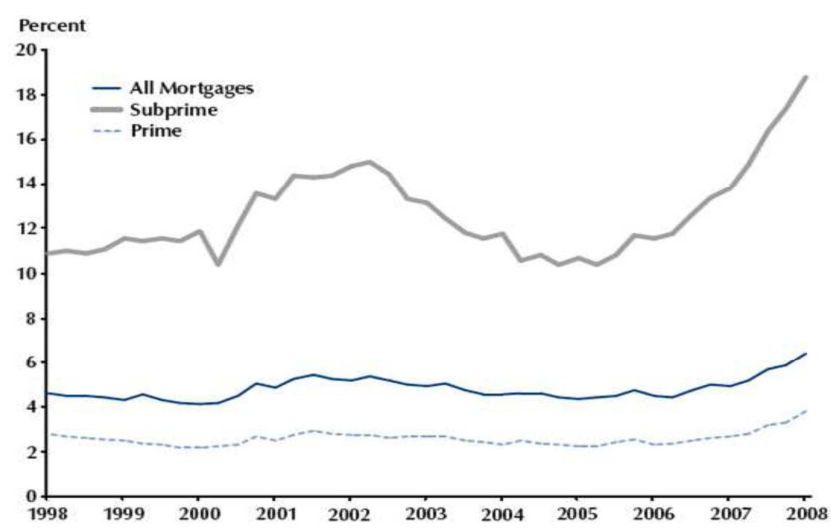

Source: Mortgage Bankers Association/Haver Analytics

Figure 2. The rate applied to mortgage credit States.

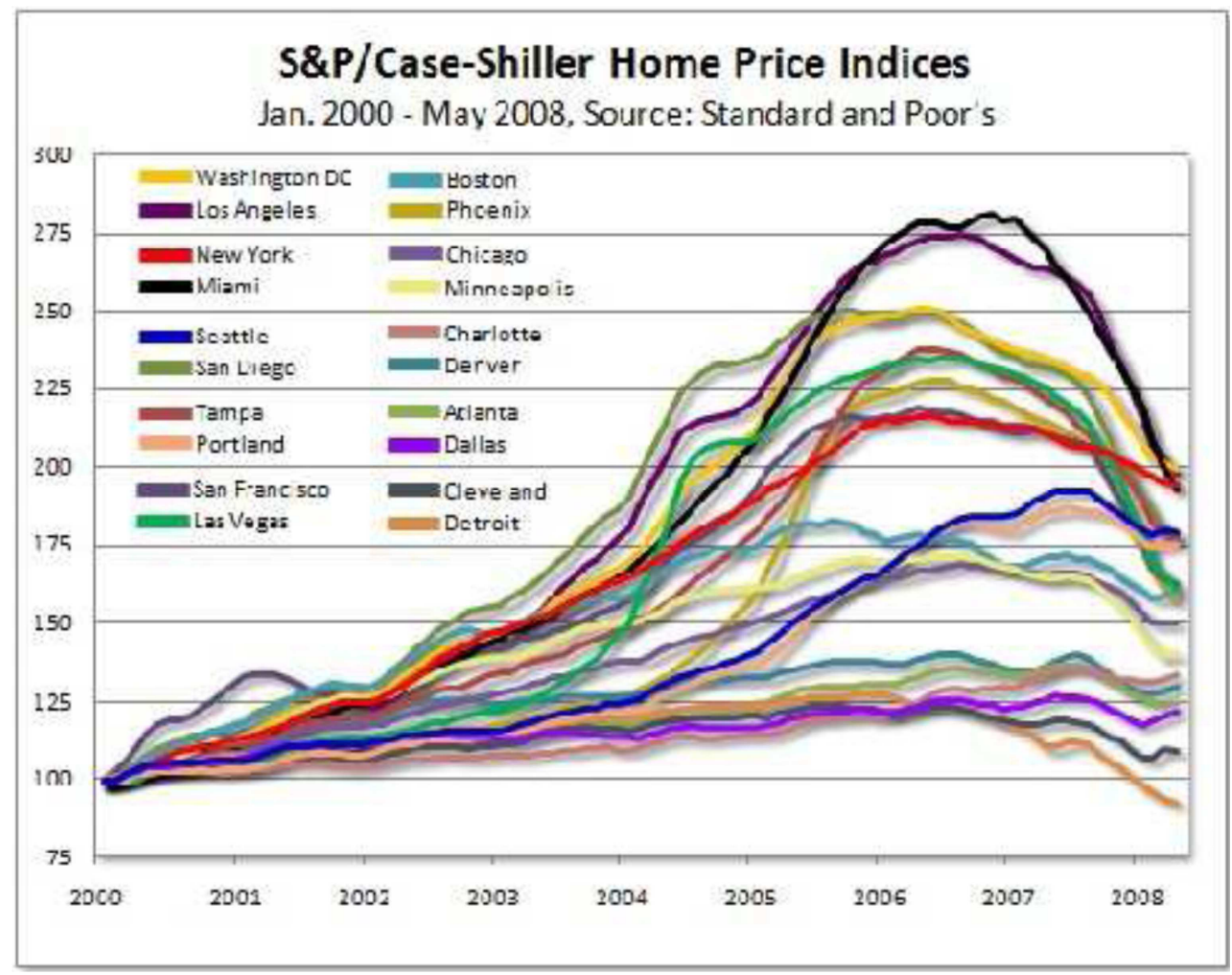

Figure 3. The fall of the index of real estate prices in major US states. 


\section{Securitization Market Activity}

\section{sBillions}

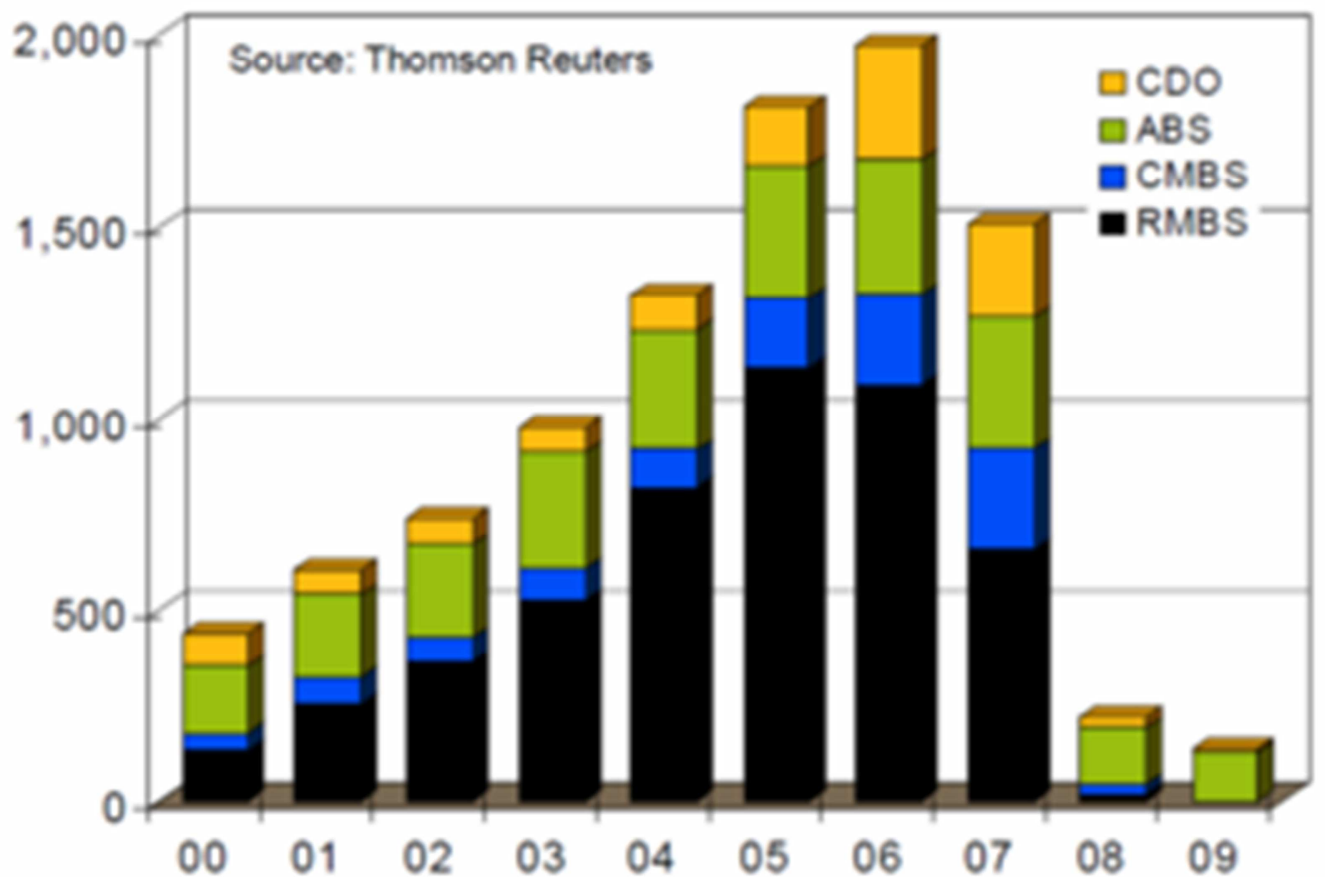

Figure 4. Securitization Market Activity.

Subprime Mortgage Crisis: "Vicious Cycles" of Foreclosure and Bank Instability

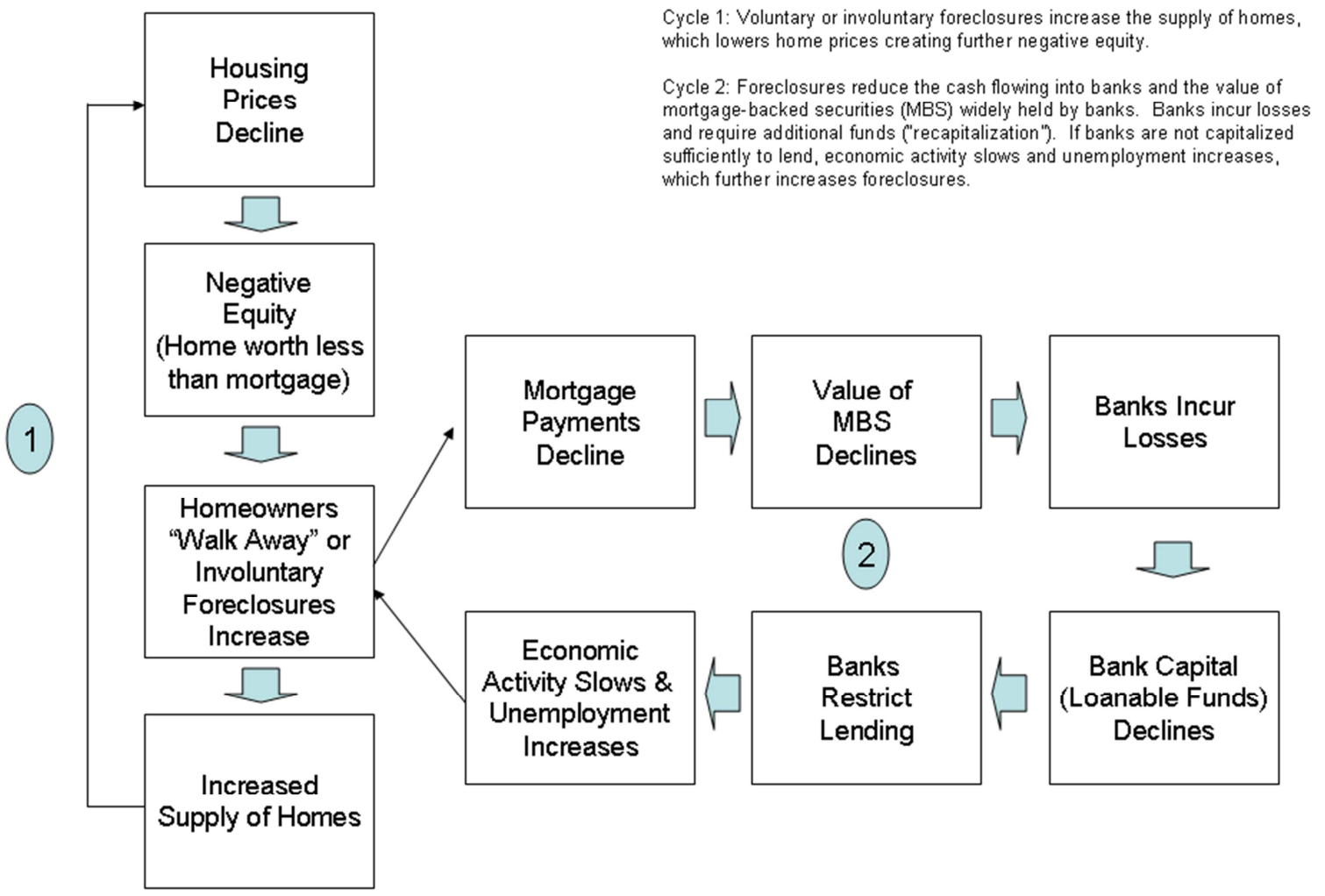

Figure 5. Subprime Mortgage Crisis. 


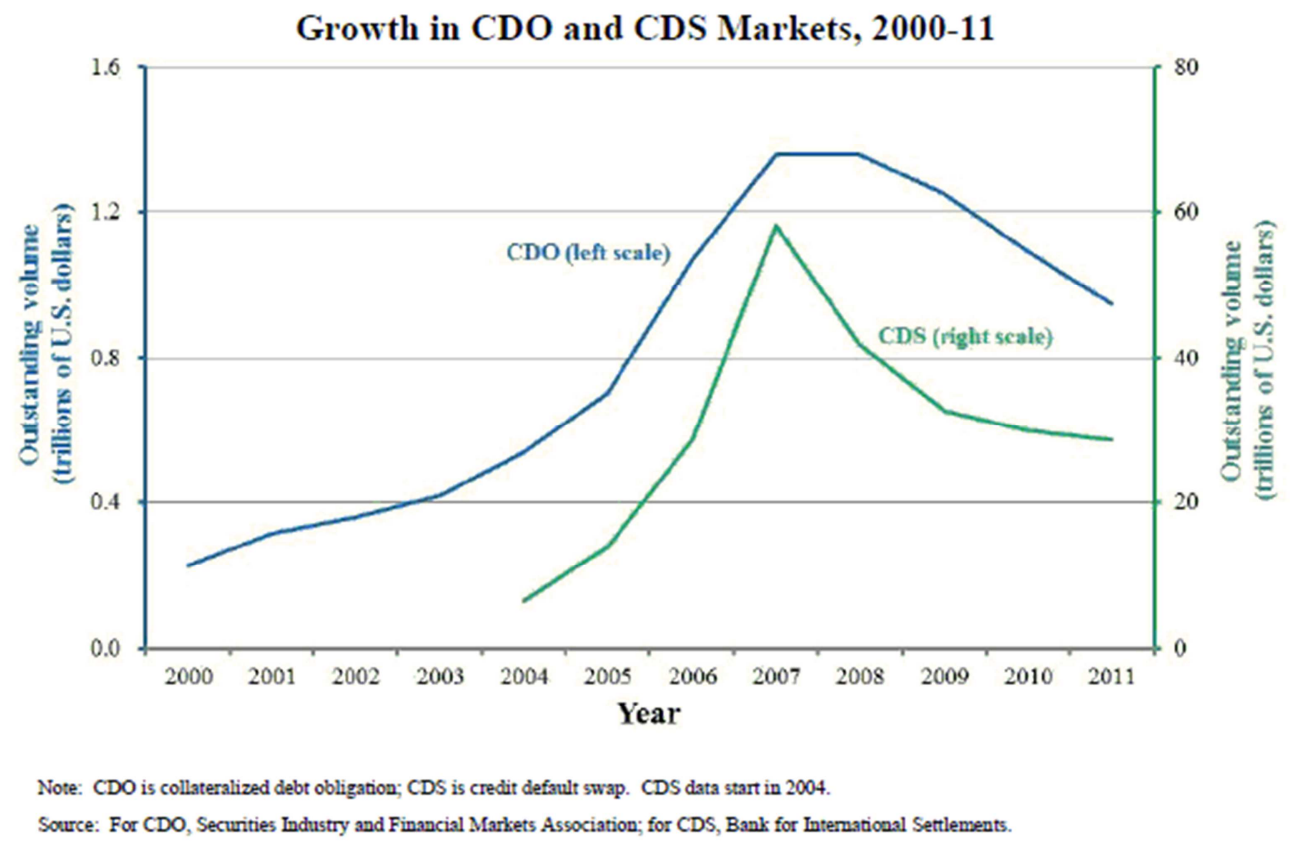

Figure 6. Growth in CDO and CDS (2000-2011).

\section{Modeling of Credit Derivatives 'CDS and CDO'}

Credits derivatives are the financial instruments which are limited by a credit event such as business failure. In comparison with the financial market, they are the main tools of securitization since they constitute a crucial part of banks' credit activity ${ }^{1}$.

In order to ensure an optimal and rational management of these complex products, the stochastic modeling and mainly the valuation of CDO and CDS have attracted the growing interest from researchers and specialists through the introduction of new methods such as the Gaussian copula which is used to model the default correlation.

\subsection{Credits Default Swap (CDS)}

Appeared in the early 1990s, credits default swaps are instruments classified as off balance sheet commitments and described as comparable transactions to insurance. They are used on the derivatives market as hedging, investment, and finally, as object of purely speculative operation.

\subsubsection{Principal and Evolution}

The CDS is a bilateral contract of protection which has to do with the case when a borrower cannot pay off the debt. In this regard, the protection buyer pays at regular intervals a premium based on the risk and the notional amount of the underlying asset until the maturity of the contract or the date of occurrence of the default. In return, the protection seller

1 The market for credit derivatives has experienced strong growth in recent years. For example, their notional amount has reached \$ 600 billion in 1999 to $\$ 4.479$ trillion in mid -2004 and 51095 billion in mid-2007. These derivatives include the CDS (credit default swaps) and CDO (Collateralized Debt Obligation). agrees to compensate the loss on the underlying credit when having a credit event ${ }^{2}$.

The most cash credit default swap contracts have a duration of 5 years while the other most traded maturities dates are 3,7 and 10 years. The CDS is a credit derivative of great importance; its price fluctuates therefore with changes in the perceived risk of the underlying instruments. The price of CDS expressed in spreads evolves in the opposite direction of the underlying value.

As a result, the CDS market has evolved in a phenomenal way. In fact, the Bank for International Settlements estimated that the CDS accounted for $\$ 13900$ billion in December 2005 , \$ 28900 billion in December 2006, and \$ 42600 billion in June 2007 and after the end of the 2007 study published by ISDA. In addition, the notional amount of CDS outstanding represents about $\$ 62.2$ trillion, which is equal to the total GDP of the world. This market has therefore taken the size of a financial bubble.

In 2008, the CDS accounted for $80 \%$ of transactions made on credit derivatives, according to a research conducted by the British Bankers Association.

The US market for CDS was thus of an amount which was equal to the total bank deposits of the whole world. Lehman Brothers bank was the first agent in the market until its bankruptcy. In addition, the CDS is considered as a root cause behind this economic collapse on September 15th, 2008, the emergence of AIG (American international group), the amplification and spread of the crisis in the financial system.

The transparency and the increasing liquidity of the CDS

2 The reimbursement by the protection seller may be in physical form (physical settlement) This form is indeed for the protection buyer to sell at par securities in default for an amount equal to the nominal value of swap. By cons, in case cash (cash settlement), the protection seller pays an amount equal to the difference between the nominal value of the swap and its market value after default. The protection buyer remains the owner of the asset. 
market have naturally paved the way to the creation of standardized CDS indexes, such as iTraxx (created in 2004) for Europe and Asia while CDX is for North America. These indices are real benchmarks of the credit market condition since they facilitate the use of trading tools ${ }^{3}$.

\subsubsection{Pricing of CDS}

The main assumptions used in the valuation of CDS are:

- The probabilities of default, interest rates and recovery rates are independent

- There is no arbitrage opportunity;

- There is a risk neutral probability;

- For each requirement, the recovery rate is the same (in most cases it is equal to $40 \%$ );

- In case of default, the bondholder requires the payment of the nominal value of the bond and accrued interest;

- There is no risk that the counterparty may default.

If entity $\mathrm{A}$ lends money to $\mathrm{B}$, so $\mathrm{B}$ must reimburse a certain amount at time $\mathrm{T}$. But if $\mathrm{A}$ wants to be protected against the risk of default of $B$, it uses an external entity $C$ which will hedge the risk by paying a periodic premium until the maturity of the swap or until the completion of a default event. So:

- If B does not default before $\mathrm{T}$, it must completely repays A: A pays money (the spread) to $\mathrm{C}$ every 3 months (for example).

- If B fails to pay beforeT, C will pay the money owed to A. In practice, even if $\mathrm{B}$ fails to repay, it may return a small portion of what it owes to A: This is called the recovery rate. In this case, $\mathrm{C}$ must reimburse to $\mathrm{A}$ only $\mathrm{N} \times(1-\mathrm{R})$.

The default leg or the variable leg 'Float Leg': is the expected present value of the payment to be made by the protection seller. So, $\mathrm{C}$ will pay $\mathrm{A}$ in case of default, if the variable leg is: $E\left(B_{\tau} \times N \times(1-R) \times 1_{(\tau \leq T)}\right)$

But if the interest rate is zero, we will have:

$$
\mathrm{JV}=\mathrm{N} \times(1-\mathrm{R}) \times \mathrm{Q}(\tau \leq \mathrm{T}) .
$$

For more clarification, $B_{\tau}$ is the zero coupon; $\tau$ is the default time of $\mathrm{B}$; $\mathrm{s}$ is the spread by an unit of nominal and the function $1_{(\tau \leq T)}$ is the indicator of default.

On the other hand, the protection buyer is often required under the terms of the contract to pay an additional premium in case of default. So if there is default with $t_{i-1} \prec \tau \prec t_{i}$, so you will have to pay the increased spread of $\left[\mathrm{t}_{\mathrm{i}-1}, \tau\right]$ because the buyer is protected in this period.

The premium leg or the 'Fixed Leg': is the expected present value of the payment to be made by the protection buyer.

Fixed Leg $=$

$$
\mathrm{E}\left(\sum_{\mathrm{i}=1}^{\mathrm{n}} \mathrm{B}_{\mathrm{t}_{\mathrm{i}}} \times \mathrm{N} \times \mathrm{s} \times \delta_{\mathrm{i}} \times 1_{\tau \succ \mathrm{t}_{\mathrm{i}}}\right)+\mathrm{E}\left(\sum_{\mathrm{i}=1}^{\mathrm{n}} \mathrm{B}_{\tau} \times \mathrm{N} \times \mathrm{s} \times \delta_{\tau} \times 1_{\mathrm{t}_{\mathrm{i}-1}<\tau<\mathrm{t}_{\mathrm{i}}}\right)
$$

3 The iTraxx and CDX indices are portfolios which are made up of a basket with 125 default swaps. The value of the index reflects the cost to hedge against default events of the index component entities. The premium payment is made each year on March 20th, June 20th, September 20th, and December 20th.
The pure premium or breakeven spread is the premium that should be paid by the protection buyer so that the contract would be fair to both parties.

$$
\mathrm{s}^{*}=\frac{\mathrm{E}\left(\mathrm{B}_{\tau} \times \mathrm{N} \times(1-\mathrm{R}) \times 1_{(\tau \leq \mathrm{T})}\right)}{\mathrm{E}\left(\sum_{\mathrm{i}=1}^{\mathrm{n}} \mathrm{B}_{\mathrm{t}_{\mathrm{i}}} \times \mathrm{N} \times \delta_{\mathrm{i}} \times 1_{\tau \succ \mathrm{t}_{\mathrm{i}}}\right)+\mathrm{E}\left(\sum_{\mathrm{i}=1}^{\mathrm{n}} \mathrm{B}_{\tau} \times \mathrm{N} \times \delta_{\tau} \times 1_{\mathrm{t}_{\mathrm{i}-1} \prec \tau \prec \mathrm{t}_{\mathrm{i}}}\right)}
$$

Based on the assumptions outlined above, we have noticed that the problem is entirely up to model the default moment of entity $B$.

The default time is assimilated as a random variable which is unpredictable, positive, and modeled according to the first arrival (first jump) of a Poisson counting process.

Furthermore, the correlation between default times is a measure of the intensity through which a number of defaults come to gather. This correlation is assumed static and constant.

The default intensity (instantaneous probability of default), of an entity, is the probability when a default occurs between $\mathrm{t}$ and $\mathrm{t}+\mathrm{dt}$ knowing that there was no default beforet. But the default time is an exponentially distributed parameter $\lambda_{i}$

Hence $\mathrm{P}(\tau \succ \mathrm{t})=\exp \left(-\int_{0}^{\mathrm{t}} \lambda_{\mathrm{s}} \mathrm{ds}\right) \quad$ or $\quad \mathrm{F}_{\mathrm{i}}(\mathrm{t})=\mathrm{P}(\tau \leq \mathrm{t})=1-\mathrm{e}^{-\lambda_{\mathrm{i}} \mathrm{t}}$ is what amounts to calculate $\lambda_{i}$. The underlying basket has a credit worthiness which even implies $\lambda_{\mathrm{i}}=\lambda, \forall \mathrm{i}$.

In practice, the spreads are rated by maturity, that is why it is assumed that the default intensity is piecewise and constant. The model is therefore calibrated to spread quotations.

\subsection{Collateralized Debt Obligation (CDO)}

CDOs are bonds which are backed debt products resulting from a relatively complex mechanism and a recent financial engineering called securitization.

\subsubsection{Principle and Benefits}

The CDO is a protection contract which concerns the default of many borrowers. It is sold in tranches representing the minimum and maximum amount of loss. A CDO is a sort of "basket of CDS": grouping a number of CDS (a hundred in practice) in a single product. So, we get a spread regularly but we will pay if a default occurs.

"Subprime" loans are gathered with other securities including mortgage normal rate ("premium") or bonds issued by companies or sovereign debt to create CDOs.

The arranger or CDO initiator is usually a bank that wishes to transfer the credit risk of its portfolio. For this purpose, it will sell its benchmark portfolio to a specialized asset management company called company "ad hoc" or Special Purpose Vehicle (SPV). This ultimately issues CDO tranches that correspond to different risk levels ranging from very high risk (junk) to very low risk (AAA). Indeed, there are four types of groups (super senior, senior, mezzanine and equity), which give rise to different remunerations according to their risk level. Each tranche is assessed by a credit rating agency and sold on this basis to 
various investors including hedge funds, pension funds, insurance companies and banks.

On the one hand, the CDO provides to the arranger or the initiator of these structured products several advantages including:

- Transfer and distribution of risk in the market.

- New funding source.

- Off-balance sheet management and by pass of prudential regulation.

- Sur notation of assets.

On the other hand, the CDOs allow investors to diversify their portfolios and invest in assets adapted to their risk-return profile.

Since its inception in the mid 1990s, the CDO market has continued to grow. Thus, on June 30th 2008, CDOs have an outstanding amount of $\$ 530000$ billion $^{4}$.

\subsubsection{Valuating Tranches of Synthetic CDOs}

The valuation of a CDO tranche actually depends on its "height" in the basket and on the number of counterparties that may be lacking in assets before reaching this tranche. A CDO tranche rating is also equivalent to the assessment of what is called the nth to default CDS. It is therefore to know the marginal probability of default over the portfolio.

To determine the portion of value, we must first estimate the losses that the portion will be subject to during the contract term and update these losses on the valuation date. Similarly, the premium payments that the tranche will receive are estimated and discounted to the valuation date.

Supposing you buy a tranche $\left[\mathrm{K}_{1}, \mathrm{~K}_{2}\right]$ of attachment point $\mathrm{K}_{1}$ and detachment point $\mathrm{K}_{2}$ with real $\mathrm{K}_{1}$ and $\mathrm{K}_{2}$ such as $0 \leq \mathrm{K}_{1} \leq \mathrm{K}_{2} \leq 1$ which pays a spread according to a well defined period, we will therefore receive a spread on the portion of the tranche "alive" (which has not made a default). In addition, you pay the portion that has been lacking in order to try in practice to estimate the value of the tranche $\left[\mathrm{K}_{1}, \mathrm{~K}_{2}\right]$ assuming that there is a so-called neutral risk probability $Q$ which came out of a calibrated model on the market by excluding any arbitrage opportunity. Moreover, we should take into consideration a portfolio of $N$ issuers having the following characteristics:

The cumulative loss of a portfolio at the moment $t$ is the quantity:

$$
\mathrm{L}_{\mathrm{t}}^{\mathrm{P}}=\sum_{\mathrm{i}=1}^{\mathrm{N}} \mathrm{N}_{\mathrm{i}}\left(1-\mathrm{R}_{\mathrm{i}}\right) 1_{\left\{\tau_{\mathrm{i}} \leq t\right\}}=\sum_{\mathrm{i}=1}^{\mathrm{N}} \mathrm{L}_{\mathrm{i}} 1_{\left\{\tau_{\mathrm{i}} \leq t\right\}}
$$

With $\mathrm{L}_{\mathrm{i}}=\mathrm{N}_{\mathrm{i}}\left(1-\mathrm{R}_{\mathrm{i}}\right), \mathrm{i}=1, \ldots . ., \mathrm{n}$ the loss associated with the default name $i$, we considered later that the total nominal portfolio was 1,i.e. $\sum_{\mathrm{i}=1}^{\mathrm{N}} \mathrm{N}_{\mathrm{i}}=1$

Leg protection: the cumulative losses in $t$ on the tranche $\left[\mathrm{K}_{1}, \mathrm{~K}_{2}\right]$, are $\mathrm{L}_{\mathrm{t}}^{\left[\mathrm{K}_{1}, \mathrm{~K}_{2}\right]}$ zero-rated when $\mathrm{L}_{\mathrm{t}}^{\mathrm{P}} \leq \mathrm{K}_{1}$ is equaled to

4 These figures are compared to the total market capitalization of the US when it was prosperous in late 2007 , before the start of the crisis 30000 billion.
$\mathrm{L}_{\mathrm{t}}^{\mathrm{P}}-\mathrm{K}_{1}$ when $\mathrm{K}_{1} \leq \mathrm{L}_{\mathrm{t}}^{\mathrm{P}} \leq \mathrm{K}_{2}$ and $\mathrm{K}_{2}-\mathrm{K}_{1}$ where $\mathrm{L}_{\mathrm{t}}^{\mathrm{P}} \geq \mathrm{K}_{2}$.

We call the cumulative loss is then defined in $t$ on the tranche $\left[\mathrm{K}_{1}, \mathrm{~K}_{2}\right]$ by:

$$
\mathrm{L}_{\mathrm{t}}^{\left[\mathrm{K}_{1}, \mathrm{~K}_{2}\right]}=\left(\mathrm{L}_{\mathrm{t}}^{\mathrm{P}}-\mathrm{K}_{1}\right)^{+}-\left(\mathrm{L}_{\mathrm{t}}^{\mathrm{P}}-\mathrm{K}_{2}\right)^{+}
$$

that is to say, a call spread (difference of two calls) on the loss of the portfolio.

Unlike a CDS, the nominal tranche is variable, namely: $\mathrm{K}_{2}-\mathrm{K}_{1}-\mathrm{L}_{\mathrm{t}}^{\left[\mathrm{K}_{1}, \mathrm{~K}_{2}\right]}$. For a given scenario, the present value of payments on the protection leg is where $\int_{0}^{\mathrm{T}} \mathrm{B}_{\mathrm{t}} \mathrm{dL}_{\mathrm{t}}^{\left[\mathrm{K}_{1}, \mathrm{~K}_{2}\right]} \mathrm{B}_{\mathrm{t}}=$ $\exp \left(-\int_{0}^{t} r_{s} d s\right)$ represents the discount factor for the period $[0, t]$ and $r_{t}$ the short-term interest rates is deterministic.

$$
\text { The Variable Leg }=\mathrm{E}\left(\int_{0}^{\mathrm{T}} \mathrm{B}_{\mathrm{t}} \mathrm{dL}_{\mathrm{t}}^{\left[\mathrm{K}_{1}, \mathrm{~K}_{2}\right]}\right)
$$

The premium leg: the payment made by the protection buyer is equal to: $\mathrm{s} \times \delta_{\mathrm{i}} \times\left(\mathrm{K}_{2}-\mathrm{K}_{1}-\mathrm{L}_{\mathrm{t}}^{\left[\mathrm{K}_{1}, \mathrm{~K}_{2}\right]}\right)$ for each premium payment date $t_{i}, i=1, \ldots ., n$ and $\delta_{i}=t_{i}-t_{i-1}$

Moreover, when a default occurs between premium payment dates and where it affects the tranche $\left[\mathrm{K}_{1}, \mathrm{~K}_{2}\right]$, the nominal amount remaining on the tranche decreases.

For example, if the name $\mathrm{j}$ is missing in $\tau_{\mathrm{j}}$ between $\mathrm{t}_{\mathrm{i}-1}$ and $t_{i}$, the coupon paid in $\tau_{j}$ is equal to: $s \times\left(\tau_{j}-t_{i-1}\right) \times \mathrm{dL}_{\tau_{j}}^{\left[\mathrm{K}_{1}, \mathrm{~K}_{2}\right]}$

$$
\mathrm{E}\left[\sum _ { \mathrm { i } = 1 } ^ { \mathrm { n } } \left(\left(\mathrm{B}_{\mathrm{t}} \times \mathrm{s} \times \delta_{\mathrm{i}} \times\right.\right.\right.
$$

The fixed leg $=\left(\mathrm{K}_{2}-\mathrm{K}_{1}-\mathrm{L}_{\mathrm{t}}^{\left[\mathrm{K}_{1}, \mathrm{~K}_{2}\right]}\right)+$

$$
\left.\left(\int_{t_{i-1}}^{t_{i}}\left(B_{t} \times s\left(t-t_{i-1}\right) d L_{t}^{\left[K_{1}, K_{2}\right]}\right)\right)\right]
$$

The fair spread is the spread that equalizes the fixed leg and the variable leg.

Modeling $\mathrm{L}_{\mathrm{t}}$ returns to model the moments of the default $\tau_{1}, \tau_{2}, \ldots$ which implies the determination of the dependence between these random variables because these default times correspond to real situations (bankruptcy, deterioration of credit rating ...).

One difficulty in assessing synthetic CDOs is to establish the distribution of CDS portfolio losses. For the distribution of losses across the portfolio, we must both know the default behavior of each name individually and their joint distribution.

\section{SKLAR Theorem}

As For a CDS, the probability distribution $\mathrm{P}(\tau \geq \mathrm{t})$ is known. So we need a consistent random variable over $[0,1]$. Let $\tau_{1}, \tau_{2} \ldots \tau_{\mathrm{n}}$ are arbitrary real random variables, then:

A function $\mathrm{C}:[0,1]^{\mathrm{n}} \rightarrow[0,1]$ is a copula if:

$$
\forall\left(\mathrm{t}_{1}, \mathrm{t}_{2}, \ldots, \mathrm{t}_{\mathrm{n}}\right), \mathrm{C}\left(\mathrm{t}_{1}, \ldots, \mathrm{t}_{\mathrm{n}}\right)=\mathrm{P}\left(\tau_{1} \leq \mathrm{t}_{1}, \ldots \tau_{\mathrm{n}} \leq \mathrm{t}_{\mathrm{n}}\right)
$$


A copula is a function of joint distribution whose margins are uniform on $[0 ; 1]$.

Gaussian copula of David X Li (1999)

The standard method of credit derivatives of pricing tranches is the "Gaussian copula" which binds the default times by underlying assets correlated with random variables. This method enables us to build a dependency structure from the marginal distribution.

$\mathrm{C}_{\Sigma}\left(\mathrm{t}_{1}, \ldots, \mathrm{t}_{\mathrm{n}}\right)=\mathrm{N}\left(\mathrm{N}^{-1}\left(\mathrm{t}_{1}\right), \ldots \ldots . \mathrm{N}^{-1}\left(\mathrm{t}_{\mathrm{n}}\right)\right) \mathrm{N}$ the distribution function centered reduced Gaussian is, $\sum$ the correlation matrix will be:

Vasicek Single factor Model (2002)

To reduce the number of parameters to estimate "correlation between each of the portfolio entities", which is $n(n-1) / 2$ in the Gaussian copula, we have proposed a factor model which is to form the default joint distribution through a constant correlation of assets.

We pose a business default indicator $i$ which is $X_{i}=\rho_{i} Z+\sqrt{1-\rho_{i}^{2}} \varepsilon_{i}$ in a way where the $X_{i}$ are the reduced centered Gaussian. $\mathrm{Z}$ and $\left(\varepsilon_{\mathrm{i}}, \forall \mathrm{i}=1\right.$.......n) are independent random variables normally distributed for means 0 and variance 1 . The $\mathrm{Z}$ factor explains all correlations between defaults of different names; the model is used therefore to refer to "a factor".

In practice, we choose $\rho_{1}=\rho_{2}=\ldots .=\rho$ to facilitate the calculations and harmonize models on markets. This correlation, $\operatorname{cor}\left(\mathrm{X}_{\mathrm{i}}, \mathrm{X}_{\mathrm{j}}\right)=\rho_{\mathrm{i}} \rho_{\mathrm{j}}$, is called correlation copula. The asset $X_{\mathrm{i}}$ is connected to the default time $\tau_{\mathrm{i}}$ of the asset $i$ by the following equation: $\mathrm{N}(\mathrm{X})=\mathrm{Q}_{\mathrm{i}}\left(\tau_{\mathrm{i}}\right)$. Indeed, every normal probability distribution is related to the original distribution in the sense that they are equivalent in percentiles expressed: $\mathrm{N}\left(\mathrm{X}_{\mathrm{i}}\right)=\mathrm{Q}_{\mathrm{i}}\left(\tau_{\mathrm{i}}\right) \rightarrow \mathrm{X}_{\mathrm{i}}=\mathrm{N}^{-1}\left(\mathrm{Q}_{\mathrm{i}}\left(\tau_{\mathrm{i}}\right)\right)$.

As we said, the $Z$ factor evaluates the dependence of the active defaults. If we assume that the value $Z$ has a given value, we will have:

$$
\begin{aligned}
& \mathrm{P}\left(\mathrm{X}_{\mathrm{i}} \prec \mathrm{X}_{\mathrm{T}} / \mathrm{Z}\right)=\mathrm{P}\left(\tau_{\mathrm{i}} \prec \mathrm{T} / \mathrm{Z}\right) \rightarrow \\
& \mathrm{N}\left[\frac{\mathrm{X}_{\mathrm{T}}-\sqrt{\rho} \mathrm{Z}}{\sqrt{1-\rho}}\right]=\mathrm{N}\left[\frac{\mathrm{N}^{-1}\left(\mathrm{Q}_{\mathrm{i}}(\mathrm{T})\right)-\sqrt{\rho} \mathrm{Z}}{\sqrt{1-\rho}}\right]
\end{aligned}
$$

Q ( $t$ ) represents the expected unconditional probability of a default before $\mathrm{T}$ and $\rho$ the average correlation of default in the overall portfolio.

If we still assume that the companies share the same distribution $\mathrm{Q}_{\mathrm{i}}=\mathrm{Q}$, we will have;

\footnotetext{
5 Generally, we interpret this as an analogy to the market model. We can see perfectly well that each performance series is linked to a common factor which is the market factor (e.g. the state of the economy in general), this factor makes them possibly weaker or stronger societies as a whole (this defines the element of Systematic risk). The rest is an idiosyncratic component of the variable specific to each asset.
}

$$
\mathrm{P}\left(\tau_{\mathrm{i}} \prec \mathrm{T} / \mathrm{Z}\right)=\mathrm{N}\left[\frac{\mathrm{N}^{-1}(\mathrm{Q}(\mathrm{T}))-\sqrt{\rho} \mathrm{Z}}{\sqrt{1-\rho}}\right]
$$

Hull and White (2004) proposed the idea of reusing Vasicek's idea presented above to assess the probability of default:

$$
\mathrm{P}(\text { défauts }=\mathrm{n})=\mathrm{C}_{\mathrm{N}}^{\mathrm{n}} \mathrm{P}_{\alpha}\left(\tau_{\mathrm{i}} \prec \mathrm{T} / \mathrm{Z}\right)^{\mathrm{n}}\left(1-\mathrm{P}_{\alpha}\left(\tau_{\mathrm{i}} \prec \mathrm{T} / \mathrm{Z}\right)\right)^{\mathrm{N}-\mathrm{n}}
$$

\section{The Result and Discussion}

The recent US subprime crisis has therefore revealed the short comings and limitations in the financial engineering mainly, in relation to the invention and innovation of these complex products and the measurement models and risk assessment.

\subsection{Analysis of CDO and CDS Failures During the Current Crisis}

\subsubsection{Opacity and Complexity of CDOs and CDS}

The complexity of credit derivatives and the structure associated with it along with the lack of CDO standardization have helped to make them opaque. In addition to this, the episodic nature of their transactions and the absence of a real secondary market provide a "real market value" as well as their inability risk assessment ${ }^{6}$.

As far as the synthetic CDOs and CDS are concerned, both parties of the contract can buy or sell their contract freely. In this respect, it is difficult to know with certainty the ultimate protection seller in a particular security.

Given the opacity of these products, the lack of reliable data and the available models, the rating agencies have been unable to accurately analyze the underlying assets of securitization vehicles and assess their risks. For this reason, they gave a label of quality (AAA rating) as regular bonds for tranches in question without considering the correlations that exist between these tranches.

This complexity and lack of transparency resulted in a lack of confidence in the credit derivatives market which weakened market liquidity and hindered the financial stability.

Furthermore, these new financial instruments have increased an operational risk during the period of the crisis ${ }^{7}$.

Indeed, the excessive and uncontrolled use of leverage on these derivatives allowed us to take very large positions with a bet of relatively modest funds which consequently facilitate the system of failures and fraud operations. The second reason is related to the complexity of financial innovation: products are more complex, the risks of fraud or simply errors are potentially significant.

\subsubsection{The Lack of Regulation and Control}

The extended market, including credit derivatives CDS and $\mathrm{CDO}$ to new agents beyond the existing prudential rules such

6 Credit derivatives were already qualified real "weapons of mass destruction" by the famous American investor Warren Buffet, in 2003.

7 The loss of 5 billion Euros by the bank Society General in 2008 . 
as hedge funds and insurance companies, has created a real financial crisis.

In general, the CDO and CDS market is not regulated and transactions are OTC. Also in this market, there is no control of the possibility for the bettor to honor its commitment by checking it has the necessary resources to cover losses upon the occurrence of a credit event. The access to CDO and CDS market is not controlled by the government. Similarly, there is no control of the total amount of contracts processed.

In summary, the CDS has contributed to the intensification of systemic risk via hyper concentration of risks on a small number of highly interconnected agents; few are both buyers and sellers of these instruments.

\subsubsection{The Error of Assessment of CDS and Tranches of CDO}

For years, until mid 2007, CDO and CDS were processed and exchanged in the credit derivatives market on the basis of the "Gaussian copula" of the Chinese mathematician David X. $\mathrm{Li}$ working at JP Morgan. In 2000 on the other hand, Li published a paper offering an ingenious formula to resolve the issue of the valuation of credits derivatives.

Consequently, the David Li formula of CDOs and CDS has become the most used method in the world of finance because of its simplicity and intuitive dependency structure. It enabled us to easily and accurately model enormous and complex risks. This equation therefore of David Li assured fluid exchange on the credit market. This formula has given a qualification (AAA) - investments without risk - mortgage funds that could have ever been, if the valuation methods of these products were referring to information and actual data records of the market.

The "Gaussian copula" of $\mathrm{Li}$ was at the heart of triggering and strengthening the recent financial crisis for several reasons:

- This copula measures the correlation risk based only on historical prices of CDS credit derivatives and not on any default history (ten years).

- Defaults are jointly distributed according to a normal distribution, which failed to correctly capture the dependence of the distributions on large losses.

- The recovery rate $(40 \%)$ of the CDS, registered during the crisis was unrealistic and optimistic, has led to inaccuracies and inconsistent valuations in situations of disturbances. They have in fact recovered $5 \%$ of their value.

- The assumption of the interest rate of default probabilities and recovery rate is unrealistic.

- The correlation is assumed unique and constant for all portfolio names. This assumption certainly facilitates the model but is not consistent with what is observed on the market.

- This model does not take into account all the variables that may influence the credit risk.

- The static nature of the Gaussian copula complicates the establishment of a dynamic hedging strategy since there is no direct way to analyze the variation in premiums for a CDO tranche from one period to another.

- The exponential law used in the valuation of CDS has certainly no economic basis (though in the "nature" has a concrete meaning).

\subsection{Some Critics of Stochastic Modeling in Finance}

The financial crisis has challenged the philosophy of risk management developed in recent years by the financial industry including stochastic modeling in finance.

\subsubsection{Critic of the Assumptions Inspired by Neoclassical Approach}

The current financial crisis has shown that the basic assumptions of the neoclassical economic theory which emerged in the late nineteenth century are very simplistic and unrealistic.

a The rationality assumption agents

This hypothesis has been widely criticized for its simplism during the current financial crisis. If the agents were perfectly rational, they did not invest in hyper complex and incomprehensible products and the markets would function ideally.

b The assumption of homogeneity

In reality, investors are not alike and do not have the same information: some invest in super senior tranches while others prefer the mezzanine tranche.

c The assumption of continuity

In the financial markets, it has been observed during the current crisis that some shares might perform jumps which are sometimes significant.

\subsubsection{Reviews of the Theoretical Foundations in Finance}

a Normal limits law and Brownian motion

During the financial crisis of 2007-2008, the risk assessment methodology of innovative products including CDS and CDO was built on the Gaussian formula which does not work in extreme and improbable situations of markets.

The Brownian motion considers market behaviors as more regular than they are in reality. Indeed, this law does not favor taking into account large-scale movements and financial crashes such as housing bubble.

This Brownian motion can create threshold effects ${ }^{8}$. This is for example the case of scoring during the current crisis for some monoline credit and some companies which have suffered threshold effects in waterfall ${ }^{9}$, etc.

Finally, the Brownian motion characterizes a closed environment without external influences. It despises cyclical trends ${ }^{10}$, but above all the movements that result from external factors affecting the financial markets: subprime crises.

b Market efficiency: one of the pillars of finance theory

\footnotetext{
8 In economics, this is the Changing slice undergoing an abrupt change due to the accumulation of small changes.

9 This clause is the basis of the credit enhancement mechanism and the financial guarantee given by the monoline insurer. It indeed guarantees bonds issued on the basis of a possible refund reflecting the position of the obligations waterfall. 10 In 2004, researchers repeated the ratings Moody's using not the KMV model typically used by the agency, but another non Brownian. AAA ratings of some products have been degraded in a proportion of 1 to 5 .
} 
Despite their good results, theories of efficient markets have been severely criticized in the financial community in recent years.

In fact, this hypothesis provides a perfect predictability of market and the impossibility of volatility that was not true during the current crisis.

Moreover, periods of speculative bubbles (like the "real estate bubble" of 2005-2007) have clarified that the financial markets sometimes are not efficient.

It has been proved to be impossible that the market agents can react simultaneously and correctly to the information they receive in the current crisis with the use of internet and all other advanced communication means.

The theory of efficiency also assumes that agents are rational i.e. reasonable, honest, and able to analyze all of the available information. This assumption from the neoclassical theory is contradicted to the financial crises including the subprime crisis that forces us to question the rationality of actors such as rating agencies and banks mortgage loans.

c The VaR's weak points

The VaR based on too short history ignores economic cycles such as the real estate market downturn in the United States.

The parametric VaR models calibrated over periods of "normal" functioning of markets are failing when exceptional, extreme, and unanticipated events occuras was the case with the failure of the Russian government in 1998 and the subprime crisis in 2007.

As a matter of fact, the VaR used to protect institutions against market fluctuations considers each institution in isolation and seems to imply that the "risk" of an institution is proportional to its size. However, it does not take into account the position of an institution in the complex network of the market (e.g. the extreme concentrations of several agents that are themselves interconnected in case of CDS crash).

\subsection{Some Measures to Solve the Modeling Crisis}

The financial industry is exposed to other models of seizures but the remaining questions in this regard are: How to dispose model assumptions that have prevailed in the financial theories? How to get out models that have dominated the financial world for many years, and build new models which are more realistic and can consider extreme and improbable crises?

Given these points, a series of measures is planned to prevent the occurrence of such crises. Thus, the proposed measures include the following:

- Improving the valuation models of credit derivative products; for this purpose, it is necessary to:

- Consider a Gaussian model with a stochastic extension of the correlation and recovery rates;

- Replace the Gaussian distribution that lacks dependence in the queues of the Student distribution;

- Introduce a copula with a Gaussian Normal Inverse factor (NIG), which is more advantageous in terms of computing time;

- Take into account the risk that the counterparty makes by default and take into consideration the situations where the payoff is subject to a number of reference entities (basket CDS);

- Propose multi periods dynamic models to better represent reality.

- Test of hypothesis: the basic assumptions of financial theories which are currently used (the hypothesis of rational expectations, the normal distribution, and the efficiency of markets) are rarely subject to confrontation tests with market realities. In this case, it is necessary to resort to experiment. Similarly, the scholars must submit the key assumptions of the financial industry to extreme simulations.

- Therefore, it is essential to understand the limitations that contain the data used and acknowledge the uncertainty that may arise. For example, a model based on five to ten years data does not provide sufficient information on the probable maximum loss in 100 years.

- Take into account the exact reality of the financial markets to develop new models for understanding, controlling and anticipating "the best". This calls into question the assumption of the completeness of markets (many risks are non-hedgeable).

- Consider multiple probability distributions: the prevailing models are based on a single probability distribution (normal distribution) to describe all types of financial assets. Instead, we must consider that each asset can have its probability distribution.

- Have the regulator disposing of the hypothesis of market efficiency as recalled George Soros: "The idea that the market tends towards equilibrium is directly responsible for the current turbulence; it encourages the regulators to flee their responsibility and rely on market mechanisms in order to correct excesses".

- Abandon the principle of self-regulation of the financial sector. This crisis is indeed due in large part in the mechanism at work that led to the collapse of the financial sector, to spiral upward, then downward, in which markets claimed to regulate themselves.

- Make sure that the VaR used by banks as the main instrument for measuring the risk is Gaussian, since it is crucial to replace it by another tool that takes into account the risk of extreme losses. For example, insurance companies commonly use power laws to assess disasters such as hurricanes, and also produce such phenomena in financial markets (the subprime crisis is proof).

- Implement next to financial mathematics complementary and interdisciplinary approaches to finance including sociology, history, genetics, neurology, physics, psychology or psychoanalysis.

- Initiate a permanent dialogue between mathematics, macroeconomics and finance in order to strengthen their presence in mathematical models that will be developed.

- Lay more emphasis on behavioral finance, which allows the incorporation of the results of all social sciences in the financial industry. The basic assumption of 
behavioral finance is that investors are not generally rational that generate failures and anomalies in the markets. Behavioral finance in this context promotes the definition of a new economic agent that does not have all the information and, therefore, is unable to predict everything.

- Focus on the moral and ethical factor, both in developing and the use of financial mathematical tools.

- Invite stochastic modeling in finance to develop and build new paradigms, enabling a better understanding of indeterminacy, uncertainty, chance, and chaos among other theories of chaos.

- Develop mathematical observatory applications that will further report of alerts.

- Manage risk by giving more prominence to human judgments and do not consider this process as a simple application of techniques and models.

\section{Conclusion}

The theoretical problems of the financial mathematics used uncontrollably and abusively by non-specialist practitioners in the field have led to misinterpretations and heavy damages. During the crisis, the rating agencies such as Moody's actually used the Brownian model to estimate the quality of financial products whereas the mathematical models were used for marketing purposes to widely sell opaque products especially complex portfolios ("CDO-squared" for example). Similarly, these models were calibrated with erroneous and very limited historical data. Finally, the misuse of such mathematical models by a very complicated computer implementation was one of the factors that aggravated the crisis.

To conclude, we can say that this crisis was an exceptional experience in the financial world; it has been the reason behind demonstrating a number of failures and shortcomings in the management and modeling of risks in the financial sector. Moreover, it has been a great opportunity to improve and renew the discipline, eliminating models which are contradicted to the facts by correcting errors occurred and trying to answer questions of regulators, managers, citizens ... etc.

\section{References}

[1] BÉCHU Thierry, 'Economics and financial markets; prospect 2010-2020', Eyrolles, organization Edition 2010.

[2] Ben HAMMOUDA Hakim, OULMANE Nassim, SADNI Jalab Mustapha, 'Crisis ... Shipwreck economists? Boeck of 2010 .

[3] CRESPELL Nicolas, 'The crisis in question', 2009, Eyrolles, 2009.

[4] ERIC François, RAYMOND Racicot THÉORET, 'Financial Econometrics Treaty: financial modeling'. University Press of Quebec, 2001.

[5] FARBER André, LAURENT Marie-Paule, OOSTERLINCK
Kim, PIROTTE Hugues, 'The essence of market finance and corporate finance', 2 edition; Synthex 2009.

[6] HERLIN, EYROLLES Philippe, 'Finance the new paradigm'. Understanding finance and economics with Mandelbrot and Taleb 'Eyrolles, organization Edition 2010

[7] JURA Michel, 'International financial technique ', 2nd edition, 2003

[8] KEELEY Brian and LOVE Patrick, 'From crisis to recovery': Causes, unfolding and Consequences of the Great Recession, OECD, 2010.

[9] KLEIN Laure, 'The subprime crises', RB, Review, Bank Edition 2008.

[10] LACOSTE Olivier, 'Understanding the financial crises', Eyrollrs. 2009.

[11] VIVIANI Jean - Laurent, 'Portfolio management', Dunod, $2^{\mathrm{e}}$ edition, 2001.

[12] COUSIN Areski, thesis; 'Risk Analysis and Coverage of the tranches of Synthetic CDO', 2008.

[13] ELKHAL Elie, graduation memory 'models and calculation methods for the valuation of synthetic CDO'. 2008.

[14] HOUNDONOUGBO Fêmin, 'Risk management - The case of credit derivatives', 2008-2009.

[15] JANNAUD Thomas; Research Stage 'interpolation of the correlation smile on CDOs' 2005; April to August 2008.

[16] SAINT-PASTEUR Paul. Memory of end of studies, 'Derivatives of Credit: a danger to financial stability', $2007-2008$.

[17] ADAM Marie-Christine and SZAFARZ Ariane, 'stock market crises, speculative bubbles and economic rationality', International Studies, vol. 20, No. 4, 1989, p. 781-790.

[18] ARMATTE Michel, Financial crisis: models of the risk and risk of model', movement of ideas and struggles, 2009.

[19] Bourven Monique and Zehr Yves, 'The banking crisis and financial regulation', 2009.

[20] Cassis Youssef, Financial crises 1929-2008', Geneva, 17 November 2009.

[21] COUSSERAN Olivier and RAHMOUNI Imène, 'The CDO market: operating methods and implications for financial stability, Bank of France $\cdot$ Financial Stability Review $・$ No. 6 , 2005.

[22] El Karaoui Nicole and Jean blanc Monique, "Financial Mathematics and the financial crisis", November, 2008.

[23] GOMBAUD Stéphane, 'Responsibility mathematics applied to finance in the crisis' Expressions No. 35, September 2010, p. 57-73.

[24] IDABOUK Ghislaine 'Financial Markets, Brownian motion, Arbitration and Martingales: birth It's Mathematical Finance corpus from 1973. October 2008.

[25] Miserey Yves, 'Some financial mathematicians are horrified of the use made of their models' le Figaro, 29/10/2008. 
[26] Nesta Lionel, 'The financial crisis causes, effects, remedies', French Economic Observatory. Department for Research on Innovation and Competition in 2009.

[27] Salmon Felix, "Receipt for the disaster: the formula which killed Wall Street", Wired, on February 23rd, 2009.

[28] Orléan-André, 'The blindness to disaster. For financial crises', March-April 2008.

[29] Olivier KLEIN, 'The current financial crisis, Novelty or repetition of history? ', 2 January 2009.
[30] KHATTAB.A, IHADIYAN.A (2015), Financial Development, Financial Instability and Economic Growth: The Case of Maghreb Countries, international journal of economics and financial issues, vol 5, issue 4 pp1043-1054.

[31] SENAT, economic study 5 - 10 December 2009 - Banking regulation to the proof of the financial crisis.

[32] Wibaut Serge, 'The economic and financial models in crisis', March 2010, Issue 78. 